\title{
CAPIM TANZÂNIA (PANICUM MAXIMUM) SOB SOMBREAMENTO E MANEJO DE CORTE
}

\author{
TANZÂNIA GRASS (PANICUM MAXIMUM) UNDER SHADDING \\ AND CUTTING HANDLING
}

\author{
Ferreira, D.J. ${ }^{1}$, Zanine, A.M. ${ }^{2}$, Souto, S.M. ${ }^{3}$ e Dias, P.F. ${ }^{4 *}$ \\ ${ }^{1}$ Universidade Federal de Viçosa/UFV. Rua Olivia de Castro 45. Bairro Clélia Bernardes. CEP 36570-000. \\ Viçosa, MG. Brasil. dany_dosanjos@yahoo.com.br \\ ${ }^{2}$ Universidade Federal de Mato Grosso. Rua Ponta Pora. Bairro Jardim Mato Grosso. CEP 78740-355. \\ Rondonópolis, MT. Brasil. anderson.zanine@ufmt.br \\ ${ }^{3}$ Empresa Brasileira de Pesquisa Agropecuária/Embrapa. Agrobiologia-RJ. BR 465, km 7. CEP-23851-970. \\ Brasil. \\ ${ }^{4}$ Estação Experimental de Seropédica da PESAGRO, BR 465, km 7. CEP 23851-000. Seropédica, RJ. Brasil. \\ pfranciscodias@hotmail.com.br
}

\section{PALAVRAS CHAVE ADICIONAIS}

Manejo forrageira. Intensidade de corte. Freqüência de corte.

\section{RESUMO}

O sucesso dos sistemas silvipastoris, dentre outros fatores, depende da identificação de gramíneas tolerantes ao sombreamento, além do conhecimento sobre manejo de pastejo. A literatura mostra resultados separados em relação às gramíneas sobre efeitos ora de sombreamento, ora de altura e intervalo de corte. O objetivo foi estudar o comportamento Panicum maximum cv. Tanzânia, sob quatro níveis de sombreamento $(0$, 25,50 e $75 \%$ ), dois intervalos (30 e 60 dias) e três alturas de corte $(15,25$ e $35 \mathrm{~cm})$. O delineamento experimental foi o de blocos ao acaso, dispostos em parcelas subdivididas com três repetições, com os níveis de sombreamento representando as parcelas e o fatorial dois intervalos e três alturas de corte, representando as subparcelas. Os resultados mostraram que o maior intervalo e maiores alturas de corte e os menores níveis de sombreamento proporcionaram mais massa seca aérea nas plantas, enquanto os maiores intervalos e níveis de sombreamento foram os responsáveis pela maior área foliar.

\section{SUMMARY}

Successful silvopastoral systems depend, among other factors, on identifying of grasses

Recibido: 6-11-07. Aceptado: 14-5-08.

\section{AdDitional KeYWORDS}

Forage management. Cutting intensity. Cutting frequency.

tolerant to shading, and knowledge of the pasture management to which they will be submitted. The literature reports separate results on grass, sometimes about the effect of shading and sometimes about the effect of cutting height and interval. The objective of the present research was to study the performance of Panicum maximum cv. Tanzânia, under four shading levels $(0,25,50$ and 75\%), two intervals (30 and 60 days) and three cutting heights $(15,25$ and $35 \mathrm{~cm})$. A randomized block design in splitplots with three replications was used, the shading levels representing the units and the factorial the cutting intervals and heights, representing subunits. The results of the treatment effects on the variables showed that the treatments in the with greater cutting interval and heights and the lower shading levels provided to more canopy dry matter in the plants, while the greatest interval and shading levels resulted in the biggest values registered for leaf area.

\section{INTRODUÇÃO}

Gramíneas forrageiras podem estar sujeitas a condição de redução de quantidades de luz que recebem. Estas condições 
são usualmente conseqüências de invasão de ervas daninhas ou estabelecimento de culturas comerciais nas áreas de pastagens, ou introdução de espécies arbóreas (sistema silvipastoril), ou mesmo, redução diurna na quantidade de luz solar devida a cobertura pelas nuvens (Dias Filho, 2004).

Um dos responsáveis pelo sucesso de sistemas silvipastoris é a escolha acertada das espécies componentes do sistema (Andrade et al., 2004; Mochi-Victor et al., 2006). No caso de espécies forrageiras, é necessário selecionar espécies produtivas, manejo adequado e ambientadas às condições edafoclimáticas da região onde serão implantadas e principalmente, tolerantes ao sombreamento (Garcia e Andrade, 2001). As braquiárias são menos afetadas pelo sombreamento, como mostraram os estudos de Lizieire et al. (1994) e Oliveira e Souto (2001) que outras gramíneas. A Brachiaria brizantha cv. Marandu é a gramínea que tem obtido melhor desempenho sob sombreamento(Andrade et al., 2001b). Outras espécies têm apresentado alta tolerância ao sombreamento, como é o caso de algumas cultivares de Panicum maximum (Castro et al., 1999; Andrade et al., 2001a), Paspalum atratrum cv. Pojuca (Costa et al., 1998) e Brachiaria mutica (Bhatt et al., 2002).

A persistência de uma pastagem é definida como a manutenção de sua produção ao longo do tempo, levando-se em consideração as variações estacionais e manejo (Matthew et al., 1999). Assim, sob pastejo, as plantas sofrem desfolhações sucessivas, cuja altura e intervalo de corte dependem principalmente do método e da taxa de lotação adotada. Portanto existe a necessidade de se compreender melhor o efeito de variações em altura e intervalo de desfolhação sobre as plantas, como forma de permitir o planejamento de estratégias de manejo mais racionais que não prejudiquem a produção e a persistência das plantas, respeitando sua ecofisiologia (Pena et al., 2007a).

Se por um lado, existe farta informação de pesquisa científica em relação ao manejo, relacionado à influência da altura e intervalo de corte no crescimento (Rêgo et al., 2004; Barbosa et al., 2004; Tonato et al., 2007), composição química (Souza et al., 2004a) e valor nutritivo (Soares et al., 2004; Souza et al., 2004b; Pauciullo et al., 2007) dos capins, por outro, esta informação é escassa em relação ao manejo das plantas crescendo em condições de diferentes níveis de sombreamento.

Dentre os diversos cultivares de $P$. maximum, as cultivares Mombaça e Tanzânia adquiriram grande destaque nas áreas de pastagens cultivadas do país, por essa razão, tem-se investido nestes cultivares boa parte dos recursos e esforços em pesquisa em anos recentes(Reis et al., 2006). Segundo Schimidt et al. (2003) e Zanine et al. (2003), o capim Tanzânia se mostrou com características interessantes como forrageira e adaptado às condições do município de Seropédica, no Estado do Rio de Janeiro, Brasil, onde se desenvolveu o presente trabalho.

Santos et al. (2006) no município deTerezina, Piauí e Castro et al. (2007) no munícipio de Betim, Minas Gerais, encontraram que o capim Tanzânia produziu mais forragem seca do que a Brachiaria brizantha cv. Marandu. Maior produção de folhas do capim Tanzânia foi observado por Montagner et al. (2006) quando comparado com outros capins (cinco cultivares de $B$. brizantha, dois de $B$. humidicola e um de $B$. decumbens).

Em vista do exposto, objetivou-se com o presente trabalho avaliar o comportamento de sete variáveis (área foliar, produção de matéria seca de parte aérea, produção de matéria seca de raiz, produção total de matéria seca, relação parte aérea: raiz, razão de área foliar e razão de massa radicular) das plantas de Panicum maximum cv. Tanzânia, sob efeito de diferentes níveis de sombreamento, altura e intervalo de corte.

\section{MATERIAL E MÉTODOS}

O estudo foi realizado sob condições de vasos no campo experimental localizado no

Archivos de zootecnia vol. 59, núm. 225, p. 82. 
município de Seropédica $\left(22^{\circ} 48^{\prime} \mathrm{S} ; 43^{\circ} 42^{\prime}\right.$ $\mathrm{W}$; altitude $33 \mathrm{~m}$ ), no estado do Rio de Janeiro, Brasil, no período de 25/01/2006 a 01/06/2006.

Usou-se solo predominante na região, Planossolo háplico distrófico arênico (Oliveira, 2008), coletado na profundidade de $0-20 \mathrm{~cm}$, seco ao ar e passado em peneira com $5 \mathrm{~mm}$ de abertura, que apresentava a seguinte característica química: $\mathrm{pH}\left(\mathrm{H}_{2} \mathrm{O}\right)=$ 4,6; $\mathrm{P}=19 \mathrm{mg} \mathrm{kg}^{-1} ; \mathrm{K}=14 \mathrm{mg} \mathrm{kg}^{-1} ; \mathrm{Ca}=1,5$ $\mathrm{cmol}_{\mathrm{c}} \mathrm{dm}^{-3}$, e $\mathrm{Mg}=1,3 \mathrm{cmol}_{\mathrm{c}} \mathrm{dm}^{-3}$. Foi misturado e aplicado uniformemente no solo, a dosagem correspondente a $1 \mathrm{Mg} \mathrm{ha}^{-1}$ de calcário dolomítico (para elevar o pH do solo para 5,5), $100 \mathrm{~kg} \mathrm{ha}^{-1}$ de $\mathrm{P}_{2} \mathrm{O}_{5}$, na forma de super-fosfato simples (20\%), $100 \mathrm{~kg} \mathrm{ha}^{-3}$ de $\mathrm{K}_{2} \mathrm{O}$, na forma de sulfato de potássio (60\%) e 40 kg de FTE BR-12*. Posteriormente, o solo foi acondicionado em vasos plásticos com capacidade de $20 \mathrm{dm}^{3}$.

O delineamento experimental adotado foi o blocos ao acaso, dispostos em parcelas subdivididas com três repetições. Os tratamentos constituíram-se de quatro níveis de sombreamento $(0,25,50$ e $75 \%)$, representando as parcelas, e dois intervalos de corte (30 e 60 dias) combinado com três alturas de corte $(15,25$ e $35 \mathrm{~cm})$ a partir da superfície do solo, representando as subparcelas.

O sombreamento artificial foi obtido com a utilização de armações galvanizadas de 1,5 m de altura e 1,5 m de comprimento e largura, revestidas de sombrite, sendo que o tratamento testemunha ( $0 \%$ ) foi mantido em ambiente externo à pleno sol. Foram medidas a quantidade de luz com radiômetro, sob diferentes tratamento de sombreamento com sombrite, confirmando os níveis de 25, 50 e $75 \%$ de sombra, com malhas iguais, respectivamente, a 30,12 e $2 \mathrm{~mm}^{2}$.

O plantio foi feito em $30 / 11 / 2005$, usando sementes da cultivar Tanzânia de Panicum maximum e após germinação foi feito um

*B 1,80\%; $\mathrm{Cu}$ 0,80\%; Fe 3,0\%; Mn 2,0\%; Mo 0,10\%; Zn 9,00\%. desbaste deixando três plantas por vaso A umidade do solo nos vasos foi mantida na capacidade de campo, durante todo período experimental.

Foi feito um corte de uniformização em 25/01/2006. As avaliações iniciaram em 22/ $02 / 2006$. Foram feitas dois cortes no intervalo de 60 dias e quatro cortes no intervalo 30 dias. Durante o período experimental, a temperatura média, a umidade relativa média, a nebulosidade média (medida de 0 a 10 ), o total de chuva recolhida e o total de evaporação na área experimental, foram respectivamente, $23,2^{\circ} \mathrm{C} ; 72,4 \% ; 5,3 ; 284,2$ mm e $485,5 \mathrm{ml}$.

Determinaram-se em cada avaliação, a área foliar (AF) e produção de massa seca da parte aérea (MSPA) em três plantas por vaso. Na última avaliação dos intervalos 30 e 60 dias também foi determinado a massa seca das raízes (MSR). A área foliar foi determinada com auxílio do aparelho $L I$ 3100 AREA METTER. A produção de massa seca da parte aérea e das raízes, foram obtidas em estufa a $65^{\circ} \mathrm{C}$, até alcançar massa constante. De posse dessas três variáveis, obtiveram-se mais quatro variáveis: relação parte aérea/raiz (PA/R), produção de matéria seca total (MST= MSPA + MSR), razão de área foliar $(\mathrm{RAF}=\mathrm{AF} / \mathrm{MST})$, e razão de massa radicular $(\mathrm{RMR}=\mathrm{MSR} / \mathrm{MST})$, totalizando assim, sete variáveis medidas nas plantas.

Análise estatística dos resultados foi feita com auxílio do programa Sisvar da Universidade Federal de Lavras. A análise estatística constou da análise de variância e de regressão com aplicação do teste F, e para as variáveis cujo teste foi significativo, foram comparadas as médias de tratamentos pelo teste Scott-Knott $(\mathrm{p}<0,05)$. Foram feitas duas análises: $1^{\mathrm{a}}$ - nos dados referentes as variáveis MSPA e AF, sob efeitos dos quatro níveis de sombreamento, dois intervalos (quatro cortes no intervalo 30 dias e dois cortes no intervalo 60 dias) e três alturas de corte; $2^{\text {a }}$ - nos dados referentes as variáveis MSPA, MSR, PA/R, MST, AF, RMR e RAF, sob efeitos dos quatro níveis

Archivos de zootecnia vol. 59, núm. 225, p. 83. 
de sombreamento, três alturas de corte, na última avaliação dos intervalos 30 e 60 dias.

\section{RESULTADOSEDISCUSSÃO}

Foram observadas diferenças significativas na MSPA do capim a favor das plantas que sofreram cortes mais altos e com maior intervalo (tabela I).

Aumento na produção de massa seca do capim Tanzânia com maior altura de corte $(50 \mathrm{~cm})$, quando comparada com 20 e $35 \mathrm{~cm}$, quando as plantas interceptavam $95 \%$ da luz incidida, também foi encontrado por Gomide et al. (2005). Souza et al. (2004c) também observaram diferenças entre alturas de corte, a maior altura $(40 \mathrm{~cm})$ proporcionou maior produção de massa seca no capim Tanzânia do que $30 \mathrm{~cm}$.

Mochi-Victor et al. (2006), baseado nos resultados das variáveis altura da planta, produção de massa seca e número de perfilho nos 289 genótipos de P. maximum, concluíram que a tolerância a sombreamento desses genótipos pode ser relacionado ao número de perfilho e altura da planta.

Nos cortes feitos com 30 dias de intervalo, a maiores alturas de corte proporcionaram maiores valores de MSPA do que no corte

Tabela I. Efeito da interação altura x intervalo de corte na produção ( $\mathrm{g} /$ vaso) de MSPA (massa seca parte aérea) nas plantas do capim Tanzânia. (Effect of the height x cutting interval interaction in the production of MSPA (dry matter of the aerial part) in the plants of the Tanzânia grass).

\begin{tabular}{ccccc}
\hline \multirow{2}{*}{$\begin{array}{c}\text { Intervalo de } \\
\text { corte (dias) }\end{array}$} & \multicolumn{4}{c}{ Altura de corte $(\mathrm{cm})$} \\
\hline 30 & 15 & 25 & 35 & Média \\
60 & $20,1^{\mathrm{bB}}$ & $22,4^{\mathrm{aB}}$ & $24,7^{\mathrm{aA}}$ & $22,4^{\mathrm{B}}$ \\
Média & $25,5^{\mathrm{aA}}$ & $26,2^{\mathrm{aA}}$ & $25,8^{\mathrm{aA}}$ & $25,8^{\mathrm{A}}$ \\
& $22,8^{\mathrm{b}}$ & $24,3^{\mathrm{a}}$ & $25,3^{\mathrm{a}}$ & -
\end{tabular}

Médias com letras diferentes, minúsculas nas linhas e maiúsculas nas colunas indicam que elas são diferentes pelo teste Scott-Knott a 5\% de probabilidade.
Tabela II. Efeito da interação altura de corte $x$ sombreamento na produção(g/vaso) de MSPA (massa seca da parte aérea) nas plantas de capim Tanzânia. (Effect of the cutting $\mathrm{x}$ shadding interaction in the production of MSPA (dry matter of the aerial part) in the plants of the Tanzânia grass).

\begin{tabular}{ccccc}
\hline \multirow{2}{*}{$\begin{array}{c}\text { Altura de } \\
\text { corte }(\mathrm{cm})\end{array}$} & \multicolumn{5}{c}{ Sombreamento $(\%)$} \\
& 0 & 25 & 50 & 75 \\
\hline 15 & $25,9^{\mathrm{aA}}$ & $22,3^{\mathrm{bB}}$ & $20,3^{\mathrm{bA}}$ & $18,9^{\mathrm{bA}}$ \\
25 & $28,5^{\mathrm{aA}}$ & $24,9^{\mathrm{aB}}$ & $21,2^{\mathrm{bA}}$ & $20,1^{\mathrm{bA}}$ \\
35 & $26,8^{\mathrm{aA}}$ & $29,8^{\mathrm{aA}}$ & $21,6^{\mathrm{bA}}$ & $22,0^{\mathrm{bA}}$ \\
Média & $27,1^{\mathrm{a}}$ & $25,7^{\mathrm{a}}$ & $21,0^{\mathrm{b}}$ & $20,3^{\mathrm{b}}$ \\
\hline
\end{tabular}

Médias com letras diferentes, minúsculas nas linhas e maiúsculas nas colunas indicam que elas são diferentes pelo teste Scott-Knott a 5\% de probabilidade.

feito a $15 \mathrm{~cm}$, enquanto que as produções de MSPA das plantas do capim Tanzânia nas alturas de corte 15 e $25 \mathrm{~cm}$ foram maiores com 60 dias, quando comparadas com 30 dias de intervalo, porém nenhuma diferença foi observada entre os intervalos de corte na altura de corte $35 \mathrm{~cm}$ (tabela I). Barbosa et al. (2007) realçaram a importância do intervalo de corte como maneira de controlar a estrutura e a composição do dossel.

Foram observadas diferenças significativas na MSPA do capim a favor das plantas que foram menos sombreadas (tabela II).

Resultados de aumentos de MSPA de outras gramíneas forrageiras tropicais com sombreamento têm sido encontrado para Panicum maximum cv. Vencedor (Carvalho et al., 1997), Setaria anceps cv. Kazangula (Castro et al., 1999), Brachiaria decumbens (Simon, 1999), B. brizantha cv. Marandu (Deinum et al., 1996; Oliveira e Souto, 2001) e Pennisetum purpureum cv. Cameron (Oliveira e Souto, 2001). O efeito do sombreamento na produção de massa seca do capim, segundo alguns autores, depende dentre outros fatores (condições edafoclimáticas locais), da espécie (Carvalho

Archivos de zootecnia vol. 59, núm. 225, p. 84. 
et al., 1997; Castro et al., 1999) ou mesmo do cultivar (Mohanty e Raí, 1995).

As produções de MSPA das plantas cortadas a 25 e $35 \mathrm{~cm}$ de altura crescidas nas condições com sombreamento 0 e $25 \%$ foram maiores que com 50 e $75 \%$ de sombra, ao passo que, quando cortadas a $15 \mathrm{~cm}$ de altura a produção a pleno sol foi maior que nos demais níveis de sombreamento (tabela II). No sombreamento $25 \%$, a produção de MSPA das plantas cortadas a $35 \mathrm{~cm}$ de altura foi maior que nas outras alturas de corte.

As maiores produções de MSPA das plantas foram obtidas quando o capim Tanzânia crescia no ambiente com menos sombra (0 e $25 \%$ ), independente dos intervalos de corte (tabela III). No mais alto nível de sombreamento as plantas produziram mais MSPA com o maior intervalo de corte (60 dias).

A interação sombreamento $\mathrm{x}$ altura de corte no intervalo de corte 30 dias, revelou que o tratamento altura de corte $25 \mathrm{~cm}$ proporcionou mais produção de MSPA a pleno sol do que nos demais níveis de sombreamento (tabela IV). No tratamento 25 cm x 30 dias foi encontrada dependência quadrática crescente da MSPA em relação aos níveis de sombreamento (S), expressa

Tabela III. Efeito da interação intervalo de corte e sombreamento na produção ( $\mathrm{g} / \mathrm{vaso}$ ) de MSPA (massa seca parte aérea) das plantas de capim Tanzânia. (Effect of the cutting interval $x$ shadding interaction in the production of MSPA (dry matter of the aerial part) in the plants of the Tanzânia grass).

\begin{tabular}{ccccc}
\hline \multirow{2}{*}{$\begin{array}{c}\text { Intervalo de } \\
\text { corte (dias) }\end{array}$} & 0 & 25 & 50 & 75 \\
\hline 30 & $26,2^{\mathrm{aA}}$ & $24,6^{\mathrm{aA}}$ & $19,7^{\mathrm{bA}}$ & $18,9^{\mathrm{bB}}$ \\
60 & $28,9^{\mathrm{aA}}$ & $27,7^{\mathrm{aA}}$ & $23,6^{\mathrm{bA}}$ & $23,1^{\mathrm{bA}}$ \\
\hline
\end{tabular}

Médias com letras diferentes, minúsculas nas linhas e maiúsculas nas colunas indicam que elas são diferentes pelo teste Scott-Knott a 5\% de probabilidade.
Tabela IV. Efeito da interação sombreamento $x$ altura de corte no intervalo 30 dias, na produção (g/vaso) de MSPA (massa seca parte aérea) das plantas de capim Tanzânia. (Effect of the shadding $x$ cutting height on the 30 days interval, in the production of MSPA (dry matter of the aerial part), in the plants of the Tanzânia grass).

\begin{tabular}{ccccc}
\hline \multirow{2}{*}{$\begin{array}{c}\text { Altura de } \\
\text { corte }(\mathrm{cm})\end{array}$} & 0 & 25 & 50 & 75 \\
\hline 15 & $24,2^{\mathrm{aA}}$ & $20,5^{\mathrm{aB}}$ & $19,1^{\mathrm{aA}}$ & $15,9^{\mathrm{aA}}$ \\
25 & $25,9^{\mathrm{aA}}$ & $22,8^{\mathrm{bB}}$ & $19,4^{\mathrm{bA}}$ & $19,2^{\mathrm{bA}}$ \\
35 & $28,3^{\mathrm{aA}}$ & $30,5^{\mathrm{aA}}$ & $20,7^{\text {aA }}$ & $21,8^{\mathrm{aA}}$ \\
\hline
\end{tabular}

Médias com letras diferentes, minúsculas nas linhas e maiúsculas nas colunas indicam que elas são diferentes pelo teste Scott-Knott a 5\% de probabilidade.

pela equação seguinte: MSPA (g/vaso)= $31,86-0,4598 \mathrm{~S}+0,004227 \mathrm{~S}^{2}(\mathrm{~F}=12,51 ; \mathrm{p}=$ 0,$\left.0025 ; \mathrm{R}^{2}=0,74\right)$, apresentando um ponto mínimo (menor MSPA) no nível de sombreamento $54,4 \%$. O tratamento 30 dias de intervalo com sombreamento $25 \%$ apresentou maior produção de MSPA na maior altura de corte (tabela IV). Estas condições devem ter proporcionado um valor de IAF maior no dossel permitindo maior interceptação de luz e eficiência fotossintética das f olhas, e como conseqüência, um maior acúmulo de biomassa seca, segundo Laca e Lemaire(2000).

Foram observadas diferenças significativas na AF (área foliar) do capim a favor das plantas cortadas com maior intervalo (tabela V).

Souza et al. (2004b) encontraram aumento do IAF (índice de área foliar) nas plantas de Tanzânia com o aumento do intervalo de corte de 4 para 10 semanas.

Nos cortes feitos com $25 \mathrm{~cm}$ de altura, o maior intervalo (60 dias) proporcionou maiores valores de AF nas plantas do capim Tanzânia do que no corte feito com menor intervalo, enquanto que nas demais alturas não foram observadas diferenças no AF entre os intervalos de corte (tabela V). 
Tabela $V$. Efeito da interação altura x intervalo de corte na AF -área foliar- $\left(\mathrm{cm}^{2} / \mathrm{vaso}\right)$ nas plantas do capim Tanzânia. (Effect of the height $x$ cutting interval interaction in the AF- foliar area in the plants of the Tanzânia grass).

\begin{tabular}{ccccc}
\hline \multirow{2}{*}{$\begin{array}{c}\text { Intervalo de } \\
\text { corte (dias) }\end{array}$} & \multicolumn{4}{c}{ Altura de corte $(\mathrm{cm})$} \\
& 15 & 25 & 35 & Média \\
\hline 30 & $2197^{\mathrm{A}}$ & $1400^{\mathrm{B}}$ & $1290^{\mathrm{A}}$ & $1.629^{\mathrm{B}}$ \\
60 & $2202^{\mathrm{A}}$ & $2642^{\mathrm{A}}$ & $2357^{\mathrm{A}}$ & $2.400^{\mathrm{A}}$ \\
\hline
\end{tabular}

Médias com letras maiúsculas diferentes nas colunas indicam que elas são diferentes pelo teste Scott-Knott a $5 \%$ de probabilidade.

No trabalho de Barbosa et al. (2007), a associação do intervalo de corte 95\% IL (capim cortado só quando havia 95\% de interceptação de luz- IL (capim com 70 cm de altura) comparado com 90 (60 cm) e 100 (85 $\mathrm{cm}$ ) de IL no pré-pastejo, com a altura de corte $25 \mathrm{~cm}$, comparada com $50 \mathrm{~cm}$, resultou em maior acúmulo de lâminas foliares nas plantas do capim Tanzânia durante período experimental. Essa diferença à favor desse tratamento, segundo os autores, foi devido altas taxas acumuladas no verão.

Pena et al. (2007b) encontraram mais massa seca de lâmina foliar manejando o capim Tanzânia no maior intervalo e altura de corte. De acordo com Lizieiri et al. (1994), menor intervalo e altura de corte implicam em maior tempo e vigor de rebrota, acarretando com o tempo pastos com menor produção de forragem, o inverso ocorrendo com as parcelas manejadas cm maior intervalo e altura de corte. Nestas condições, o pasto retêm mais superfície fotossintética e o torna mais persistente.

Foram observadas diferenças significativas na AF (área foliar) do capim a favor das plantas cortadas nos ambientes mais sombreados (tabela VI).

AF das plantas cortadas a $15 \mathrm{~cm}$ de altura crescidas nas condições com sombreamento $75 \%$ foram maiores que as crescidas nos demais níveis de sombreamento e nas demais alturas de corte que não diferenciaram entre si (tabela VI).

Morita et al. (1994) observaram que AF de C. dactylon, Paspalum notatum e $P$. dilatatum aumentou com o acréscimo do sombreamento, corroborando com os resultados encontrados por Mohanty e Raí (1995) para essas espécies mais Stenotaphrum secundata. Oliveira e Souto(2001) registraram maiores valores de AF para Coastcross 1 e $P$. purpureum cv. Cameron no nível de sombreamento 25\%, enquanto para $B$. brizantha cv. Marandu foi 50\%. Lizieiri et al. (1994) estudaram em condições controladas, o comportamento de gramíneas forrageiras (Digitaria spp. e Brachiaria brizantha cv. Marandu) na sombra e concluíram que a tolerância ao sombreamento depende da espécie considerada.

A interação sombreamento x intervalo x altura de corte revelou que o tratamento altura de corte $15 \mathrm{~cm}$ com 30 dias de intervalo proporcionou maior AF com $75 \%$ de sombreamento do que com os demais níveis (tabela VII). Foi encontrada no tratamento altura de corte $15 \mathrm{~cm}$ com 30 dias de intervalo de corte, dependência da AF linear e positiva em relação sombreamento, expressa

Tabela VI. Efeito da interação altura de corte x sombreamento na AF -área foliar( $\left.\mathrm{cm}^{2} / \mathrm{vaso}\right)$ nas plantas de capim Tanzânia. (Effect of the cutting height $x$ shadding interaction in the FA- foliar area in the plants of the Tanzânia grass).

\begin{tabular}{ccccc}
\hline \multirow{2}{*}{$\begin{array}{c}\text { Altura de } \\
\text { corte }(\mathrm{cm})\end{array}$} & 0 & 25 & 50 & 75 \\
& & & & \\
\hline 15 & $1272^{\mathrm{bA}}$ & $1716^{\mathrm{bA}}$ & $2144^{\mathrm{bA}}$ & $3663^{\mathrm{aA}}$ \\
25 & $1380^{\mathrm{AA}}$ & $1644^{\mathrm{aA}}$ & $2271^{\mathrm{aA}}$ & $1960^{\mathrm{aB}}$ \\
35 & $751^{\mathrm{aA}}$ & $1497^{\mathrm{aA}}$ & $2158^{\mathrm{aA}}$ & $2175^{\mathrm{aB}}$ \\
Média & $1134^{\mathrm{b}}$ & $1619^{\mathrm{b}}$ & $2191^{\mathrm{a}}$ & $2599^{\mathrm{a}}$ \\
\hline
\end{tabular}

Médias com letras diferentes, minúsculas nas linhas e maiúsculas nas colunas indicam que elas são diferentes pelo teste Scott-Knott a $5 \%$ de probabilidade.

Archivos de zootecnia vol. 59, núm. 225, p. 86. 
Tabela VII. Efeito da interação sombreamento $x$ altura de corte no intervalo 30 dias, na produção de $\mathrm{AF}$-área foliar- $\left(\mathrm{cm}^{2}\right)$ vaso) das plantas de capim Tanzânia. (Effect of the shadding $x$ cutting height interaction in 30 days, in the production of AF -foliar area- in plants of the Tanzânia grass).

\begin{tabular}{crrrr}
\hline \multirow{2}{*}{$\begin{array}{c}\text { Altura de } \\
\text { corte }(\mathrm{cm})\end{array}$} & \multicolumn{5}{c}{ Sombreamento (\%) } \\
& 0 & 25 & 50 & 75 \\
\hline 15 & $1145^{\mathrm{bA}}$ & $1616^{\mathrm{ba}}$ & $1932^{\mathrm{bA}}$ & $4095^{\mathrm{aA}}$ \\
25 & $1002^{\mathrm{aA}}$ & $1469^{\mathrm{aA}}$ & $1732^{\mathrm{aA}}$ & $1396^{\mathrm{aB}}$ \\
35 & $556^{\mathrm{aA}}$ & $1229^{\mathrm{aA}}$ & $1746^{\mathrm{aA}}$ & $1627^{\mathrm{aB}}$ \\
\hline
\end{tabular}

Médias com letras diferentes, minúsculas nas linhas e maiúsculas nas colunas indicam que elas são diferentes pelo teste Scott-Knott a $5 \%$ de probabilidade.

pela equação: $\mathrm{AF}\left(\mathrm{cm}^{2} /\right.$ vaso $)=18,62+$ $14,2773 \mathrm{~S}\left(\mathrm{~F}=12,35 ; \mathrm{p}=0,0056 ; \mathrm{R}^{2}=0,55\right) . \mathrm{O}$ tratamento 30 dias de intervalo com sombreamento $75 \%$ também apresentou maior AF na menor altura de corte (tabela VII).

Não foram observados efeitos significativos de sombreamento, altura e intervalo de corte nas variáveis MSPA (massa seca parte aérea), PA/R (relação parte aérea/raiz) e RMR (razão de massa radicular).

Interessante esse resultado relacionado à MSPA, baseado em um único corte (último corte dos intervalos 30 e 60 dias), quando ele é comparado com àqueles mostrados anteriormente para MSPA, baseado em quatro cortes do intervalo 30 dias e dois cortes do intervalo 60 dias, mostrando que um único corte não representou os efeitos dos tratamentos na produtividade da biomassa seca do capim.

Resultados significativos da interação sombreamento $\mathrm{x}$ altura $\mathrm{x}$ intervalo de corte na MSR (massa seca radicular) são mostrados na tabela VIII.

A produtividade da parte aérea é reflexo do que acontece com o sistema radicular, pois ambos interagem. Logo, qualquer fator que limite o crescimento de raízes pode prejudicar a produção de massa seca da planta forrageira (Giacomini et al., 2005). Pelo conhecimento prévio do crescimento e da distribuição do sistema radicular, podese orientar práticas que visem aumentar a perenidade e produtividade da pastagem no sistema de produção (Da Costa et al., 1983). As raízes devem ser estudadas em virtude de sua elevada importância na capacidade de armazenar carboidratos e proteínas, o que influencia diretamente na rebrotação após desfolhação (Giacomini et al., 2005). Segundo Richards (1993), estudos com plantas C3 e C4 têm mostrado que o crescimento de raízes cessa após remoção de cerca de 50\% ou mais sua área foliar. Portanto, é inevitável a redução no crescimento do sistema radicular imediatamente após a desfolhação.

Jank et al. (2006) estudaram o comportamento das variáveis, massas secas, total e foliar e de raízes no último corte, porcentagem de folhas, altura das plantas, número de perfilhos e valores SPAD em 25

Tabela VIII. Efeito da interação sombreamento x altura x intervalo corte na MSR -massa seca radicular-(g/vaso). (Effect of the shadding $x$ cutting interval interaction in the DMRdry matter of the root).

\begin{tabular}{|c|c|c|c|c|}
\hline \multirow{3}{*}{$\begin{array}{l}\text { Altura de } \\
\text { corte }(\mathrm{cm})\end{array}$} & \multicolumn{4}{|c|}{ Sombreamento (\%) } \\
\hline & \multicolumn{4}{|c|}{ Intervalo de corte 30 dias } \\
\hline & 0 & 25 & 50 & 75 \\
\hline 15 & $33,1^{\mathrm{aB}}$ & $34,9^{\text {aA }}$ & $37,3^{\mathrm{aA}}$ & $33,7^{\mathrm{aA}}$ \\
\hline 25 & $39,0^{\mathrm{aA}}$ & $31,0^{\text {aA }}$ & $38,7^{\text {aA }}$ & $30,3^{\mathrm{aA}}$ \\
\hline \multirow[t]{3}{*}{35} & $29,7^{\mathrm{aB}}$ & $34,1^{\text {aA }}$ & $29,3^{\mathrm{aB}}$ & $33,2^{2 \mathrm{~A}}$ \\
\hline & \multicolumn{4}{|c|}{ Intervalo de corte 60 dias } \\
\hline & 0 & 25 & 50 & 75 \\
\hline 15 & $34,7^{\mathrm{aB}}$ & $37,0^{\text {aA }}$ & $28,9^{\text {aA }}$ & $34,0^{\mathrm{aB}}$ \\
\hline 25 & $27,7^{\mathrm{aB}}$ & $35,3^{\text {aA }}$ & $32,3^{\text {aA }}$ & $40,0^{\mathrm{aA}}$ \\
\hline 35 & $43,3^{\mathrm{aA}}$ & $30,7^{\mathrm{bA}}$ & $35,3^{\mathrm{bA}}$ & $28,3^{\mathrm{bB}}$ \\
\hline
\end{tabular}

Médias com letras diferentes, minúsculas nas linhas e maiúsculas nas colunas, em cada intervalo, indicam que elas são diferentes pelo teste Scott-Knott a $5 \%$ de probabilidade. 
genótipos de $P$. maximum sob efeitos de três níveis de sombreamento (0, 50 e 70\%), concluíram que a variável massa seca de raízes é importante na seleção de genótipos em condições de sombreamento, por ter sido a variável que mais foi afetada pelos níveis de sombreamento.

Tratamento 30 dias de intervalo de corte a pleno sol mostrou que as plantas do capim Tanzânia apresentaram mais MSR quando foram cortadas na altura de corte $25 \mathrm{~cm}$ (tabela VIII). Foi possível estabelecer uma dependência quantitativa entre MSR com as alturas de corte, a mesma foi da ordem seguinte: $\mathrm{MSR}$ (g/vaso) $=-3,688+3,5867 \mathrm{~A}$ $-0,07517 A^{2}\left(F=14,96 ; p=0,0047 ; R^{2}=0,83\right)$. Desta equação quadrática decrescente, deduziu-se o ponto máximo da curva (23,9 $\mathrm{cm})$, valor este que define a altura de corte que se espera obter o máximo valor de MSR. Com 30 dias de intervalo e as plantas crescendo no nível de sombreamento 50\%, os maiores valores de MSR foram encontrados nas menores alturas de corte (15 e 25 $\mathrm{cm})$, que não diferiram entre si.

No tratamento que as plantas foram submetidas a céu aberto e cortadas com 60 dias de intervalo entre os cortes, a maior altura de corte $(35 \mathrm{~cm})$ proporcionou a maior produção de MSR, comparada com as outras alturas, que não diferenciaram entre si (tabela VIII). Houve uma regressão significativa $\left(F=63,66 ; p=0,0001 ; R^{2}=0,95\right)$ entre a MSR e as alturas de corte, da ordem seguinte: $\operatorname{MSR}(\mathrm{g} /$ vaso $)=88,338-5,3333 \mathrm{~A}$ $+0,1158 A^{2}$. Desta equação deduz-se que a produção mínima de MSR nesse tratamento pode ser atingida com o corte feito a $23 \mathrm{~cm}$ de altura. Com 60 dias de intervalo e no mais alto nível de sombreamento (75\%), a maior MSR foi alcançada com $25 \mathrm{~cm}$ de altura de corte.

Plantas do capim Tanzânia cortadas na menor intensidade de pastejo $(35 \mathrm{~cm}$ de altura) e com menor freqüência (cada 60 dias), apresentaram mais MSR no sombreamento $0 \%$ do que nos demais níveis de sombreamento (tabela VIII). Lizieiri et al.
Tabela IX. Efeito da interação sombreamento $x$ altura no intervalo corte 30 dias na MST matéria seca total- (g/vaso). (Effect of the cutting interval $x$ shadding in the 30 days cutting in MST- total dry matter).

\begin{tabular}{ccccc}
\hline \multirow{2}{*}{$\begin{array}{c}\text { Altura de } \\
\text { corte }(\mathrm{cm})\end{array}$} & \multicolumn{4}{c}{ Sombreamento $(\%)$} \\
\hline 15 & 0 & 25 & 50 & 75 \\
\hline 25 & $54,2^{\mathrm{aA}}$ & $50,3^{\mathrm{aB}}$ & $55,5^{\mathrm{aA}}$ & $51,7^{\mathrm{aA}}$ \\
35 & $67,6^{\mathrm{aA}}$ & $58,0^{\mathrm{aB}}$ & $56,7^{\mathrm{aA}}$ & $53,1^{\mathrm{AA}}$ \\
& $50,3^{\mathrm{bA}}$ & $72,0^{\mathrm{aA}}$ & $45,0^{\mathrm{bA}}$ & $57,0^{\mathrm{bA}}$ \\
\hline
\end{tabular}

Médias com letras diferentes, minúsculas nas linhas e maiúsculas nas colunas, indicam que elas são diferentes pelo teste Scott-Knott a $5 \%$ de probabilidade.

(1994) comparando a produção de raízes dos capins Digitaria swazilandensis cv. FL 556 e D. decumbens cv. Transvala crescendo sob quatro níveis de sombreamento (0, 25, 50 e 75\%), também encontraram na avaliação feita aos 240 dias após o plantio que as maiores produções de massa seca de raízes dos capins foram a pleno sol.

Segundo Marshal e Sagar (1965) em plantas sem desfolhas de azevém (Lolium multiflorum), o sistema radicular foi o principal dreno dos assimilados de suas folhas individuais, enquanto nas desfolhadas foram os perfilhos cortados.

Resultados significativos da interação sombreamento $\mathrm{x}$ altura de corte, no intervalo de corte 30 dias na MST (massa seca total= MSPA + MSR), são mostrados na tabela IX.

No tratamento que as plantas foram cortadas a cada 30 dias, o melhor resultado da MST foi obtido no nível de sombreamento $25 \%$ e com altura de corte de $35 \mathrm{~cm}$.

Plantas produziram mais MST no intervalo de corte 60 dias (70,7 g/vaso) do que no 30 dias (50,3 g/vaso), quando foram crescidas a céu aberto e cortadas na altura de corte $35 \mathrm{~cm}$. Resultados similares dos efeitos do maior intervalo e altura de corte para MSPA (tabela I) e MSR (tabela VIII)

Archivos de zootecnia vol. 59, núm. 225, p. 88. 
foram mostrados anteriormente.

Resultados significativos da interação sombreamento $\mathrm{x}$ intervalo de corte na RAF (razão de área foliar= AF/MST), são apresentados na (tabela $\mathbf{X}$ ).

RAF, que representa o tamanho da superfície assimilatória em relação a MST, apresentou no presente experimento valores mais altos em plantas de Tanzânia submetidas à níveis mais altos (50e 75\%) de sombreamento (tabela X), isto indica que as plantas expandiram as suas folhas a fim de procurar compensar a menor radiação para conseguirem atingir um nível de fotossíntese suficiente para equiparar o incremento de MST nesses níveis de sombreamento.

Foram observadas diferenças significativas na RAF quando as plantas foram cortadas com maior intervalo, exceto no nível de sombreamento $50 \%$.

A área foliar (AF) das plantas crescidas a pleno sol e com a menor altura de corte (15 $\mathrm{cm})$ foi maior quando cortada com 60 dias (1647 $\mathrm{cm}^{2} /$ vaso) de intervalo do que quando cortada com 30 dias ( $464 \mathrm{~cm}^{2} /$ vaso).

\section{BIBLIOGRAFIA}

Andrade, C.M.S., Garcia, R., Couto, L. e Pereira, O.G. 2001a. Fatores limitantes ao crescimento do capim-Tanzânia em um sistema agrosilvipastoril com eucalipto, na região dos cerrados de Minas Gerais. Rev. Bras. Zootecn., 30: 1178-1185.

Andrade, C.M.S., Garcia, R., Pereira, O.G. e Souza, A.L. 2001b. Desempenho de gramíneas forrageiras e do estilosantes mineirão em sistemas agrossilvipastoris com eucalipto. Em: Reunião Anual da Sociedade Brasileira de Zootecnia, 38. 2001. Piracicaba. Anais. Videolar. São Paulo.

Andrade, C.M.S., Valentim, J.F., Carneiro, J.C. e Vaz, F.A. 2004. Crescimento de gramíneas e leguminosas forrageiras tropicais sob sombreamento. Pesqui. Agropecu. Bras., 39: 263-270.

Barbosa, R.A., Nascimento Junior, D., Silva, S.C., Euclides, V.P.B., Fonseca, D.M., Marcelino, K.R.A., Difante, G.S., Lopes, B.A., Silveira, M.C.T. e Pena, K.S. 2004. Caracterização
Tabela X. Efeito de sombreamento e intervalo de corte na RAF $\left(\mathrm{cm}^{-2} / \mathrm{g}\right)$ - razão de área foliar. (Effect of shadding and cutting interval in the RAF- foliar area ratio).

\begin{tabular}{cccccc}
\hline \multirow{2}{*}{$\begin{array}{c}\text { Altura de } \\
\text { corte }(\mathrm{cm})\end{array}$} & 0 & 25 & 50 & 75 & Media \\
\hline 30 & $6,3^{\mathrm{aB}}$ & $10,9^{\mathrm{aB}}$ & $20,8^{\mathrm{aA}}$ & $15,3^{\mathrm{aB}}$ & $13,3^{\mathrm{B}}$ \\
60 & $20,8^{\mathrm{aA}}$ & $20,8^{\mathrm{aA}}$ & $26,3^{\mathrm{aA}}$ & $27,7^{\mathrm{aA}}$ & $23,9^{\mathrm{A}}$ \\
Média & $13,6^{\mathrm{b}}$ & $15,9^{\mathrm{b}}$ & $23,6^{\mathrm{a}}$ & $21,5^{\mathrm{a}}$ & - \\
\hline
\end{tabular}

Médias com letras diferentes, minúsculas nas linhas e maiúsculas nas colunas, indicam que elas são diferentes pelo teste Scott-Knott a 5\% de probabilidade.

\section{CONCLUSÃO}

Recomenda-se a introdução do capim Tanzânia em sistemas similares as condições edafoclimáticas estudadas, desde que o nível de sombreamento não exceda $25 \%$, e o capim seja manejado com altura acima de 25 cm e com intervalo de corte mínimo de 60 dias.

morfogênica e estrutural do capim-Tanzânia submertido a combinações de intensidade e freqüência de desfolhação. Em: Reunião Anual da Sociedade Brasileira de Zootecnia, 41. 2004. Campo Grande. Anais. SBZ. Campo Grande.

Barbosa, R.A., Nascimento Junior, D., Euclides, V.P.B., Silva, S.C., Zimmer, A.H. e Torres Junior, R.A.A. 2007. Capim-tanzânia submetido a combinações entre intensidades e freqüências de pastejo. Pesqui. Agropecu. Bras., 42: 263-270.

Bhatt, R.K., Misra, L.P., Vandana, I. and Tiwari, H.S. 2002. Growth and biomass production in tropical range grasses and legumes under stress environment. Indian J. Plant Physi., 7: 349-353.

Carvalho, M.M., Silva, J.L.O. e Campos Junior, B.A. 1997. Produção de matéria seca e composição mineral da forragem de seis gramíneas tropicais estabelecidas em um sub-bosque de angicovermelho. Rev. Bras. Zootecn., 26: 13-218.

Castro, C.R.C., Garcia, R., Carvalho, M.M. e Couto, L. 1999. Produção forrageira de gramíneas

Archivos de zootecnia vol. 59, núm. 225, p. 89. 


\section{FERREIRA, ZANINE, SOUTO E DIAS}

cultivadas sob luminosidade reduzida. Rev. Bras. Zootecn., 28: 919-927.

Castro, G.H.F., Rodriguez, N.M., Gonçalves, L.C., Mauricio, R.M., Carvalho, W.T.V. e Teixeira, A.M. 2007. Características agronômicas do capim Tanzânia em cinco diferentes idades. Em: Reunião Anual da Sociedade Brasileira de Zootecnia, 44. 2007. Jaboticabal. Anais. SBZ. Jaboticabal.

Costa, N.L., Townsend, C.R., Magalhães, J.A. e Pereira, R.G.A. 1998. Avaliação agronômica de gramíneas forrageiras sob sombreamento de seringal adulto. Em: Congresso Brasileiro em Sistemas Agroflorestais, 2. Belém. Anais. EMBRAPA-CPATU. Belém. pp. 201-203.

Da Costa, N.A., Corsi, M. e Faria, V.P. 1983. Efeito da altura e intervalo de cortes sobre a produção de massa seca aérea e peso da matéria orgânica do sistema radicular do capim andropogon ( $A n$ dropogon gayanus, Kunth). O Solo, 75: 5-10.

Deinum, B., Sulastri, R.D., Zeinab, M.H.J. and Maasen, A. 1996. Effects of light intensity on growth, anatomy and forage quality of two tropical grasses (Brachiaria brizantha and Panicum maximum var. Trichoglume). Neth. J. Agr. Sci., 44: 111-124.

Dias Filho, M.B. 2004. Growth and biomass allocation of the $\mathrm{C}_{4}$ grasses Brachiaria brizantha and $B$. humidicola under shade. Pesqui. Agropecu. Bras., 35: 2335-2341.

Garcia, R. e Andrade, C.M.S. 2001. Sistemas silvipastoris na Região Sudeste. Em: Sistemas Agroflorestais Pecuários: Opções de Sustentabilidade para Áreas Tropicais e Subtropicais. Juiz de Fora. Anais. Embrapa Gado de Leite. Juiz de Fora. pp. 173-187.

Giacomini, A.A., Mattos, W.T., Mattos, H.B., Werner, J.C., Cunha, E.A. e Carvalho, D.D. 2005. Crescimento de raízes de capins Aruana e Tanzânia submetidos a duas doses de nitrogênio. Em: Reunião Anual da Sociedade Brasileira de Zootecnia, 42. 2005. Goiânia. Anais. SBZ. Goiânia.

Gomide, C.A.M., Costa, C.X., Santos, N.L., Rangel, J.H.A. e Muniz, E.N. 2005. Estrutura da vegetação e produção de forragem em capimTanzânia sob irrigação observando três alturas de resíduo. Em: Reunião Anual da Sociedade Brasileira de Zootecnia, 42. 2005. Goiânia. Anais. SBZ. Goiânia.
Jank, L., Gontijo Neto, M.M., Resende, M.D.V., Laura, V.A., Calixto, S., Resende, R.M.S. e Valle, C.B. 2006. A exploração de algumas características agronômicas e morfológicas na seleção de Panicum maximum para condições silvipastoris. Em: Reunião Anual da Sociedade Brasileira de Zootecnia, 43. 2006. João Pessoa. Anais. SBZ. João Pessoa.

Laca, E.A. and Lemaire, G. 2000. Measuring sward structure. In: Mannetje, L.; Jones, R.M. (eds.). Field and Laboratory Methods for Grassland and Animal Production Research. CAB International. Wallingford. pp. 103-122.

Lizieiri, R.C., Dias, P.F. e Souto, S.M. 1994. Comportamento de gramíneas forrageiras tropicais na sombra. Em: Reunião Anual da Sociedade Brasileira de Zootecnia, 31. 1994. Maringá. Anais. SBZ. Maringá. pp. 265-267.

Marshall, C. and Sagar, G.R. 1965. The influence of defoliation on the distribution of assimilates in Lolium multiflorum Lam. Ann. Bot-London, 29: 365-372.

Mattheus, C., Assuero, S.G., Black, C.K. and Sackville, H. 1999. Tiller dynamics of grazed swards. In: Congress on Grassland Ecophysiology and Grazing Ecology. 1999. Curitiba. Proceedings. UFPR/UFRGS. Curitiba. pp. 109-133.

Mochi-Victor, D., Jank, L., Lempp, B. e Resende, M.D.V. 2006. Efeito da redução da luminosidade no melhoramento de Panicum maximum. Em: Reunião Anual da Sociedade Brasileira de Zootecnia, 43. 2006. João Pessoa. Anais. SBZ. João Pessoa.

Mohanty, C.R. and Rai, B.G.M. 1995. Response of lawn grasses to various intensities of light. Orisssa J. Horticulture, 23: 45-53.

Montagner, D.B., Nascimento Junior, D., Silva, S.C., Valle, C.B., Silveira, M.C.T., Pena, K.S., Zanine, A.M., Silva, W.L. e Fonseca, D.M. 2006. Caracterização morfogênica de gramíneas dos gêneros Brachiaria e Panicum. Em: Reunião Anual da Sociedade Brasileira de Zootecnia, 43. João Pessoa. Anais. SBZ. João Pessoa.

Morita, O., Goto, M. and Ehara, H. 1994. Growth and matter production of pasture plants grown under reduced light conditions of summer season. B. Faculty of Bioresources, 12: 11-20.

Oliveira, F.L. e Souto, S.M. 2001. Efeito sombreamento no crescimento inicial de gramíneas forrageiras tropicais. Pesqui. Agropecu.

Archivos de zootecnia vol. 59, núm. 225, p. 90. 
Gaúcha, 7: 221-226.

Oliveira, J.B. 2008. Sistema brasileiro de classificação de solos. http://200.20.158.8/ blogs/sibcs. Acesso em 07/04/2008.

Pauciullo, D.S.C., Carvalho, C.A.B., Aroeira, L.J.M., Morenz, M.J., Lopes, F.C.F. e Rossiello, R.O.P. 2007. Morfofisiologia e valor nutritivo do capimbraquiária sob sombreamento natural e a sol pleno. Pesqui. Agropecu. Bras., 42: 573-579.

Pena, K.S., Nascimento Junior, D., Silva, S.C., Euclides, V.P.B., Zanine, A.M., Silveira, M.C.T., Montagner, D.B., Sousa, B.M.L. e Silva, W.L. 2007a. Morfogênese em Panicum maximum cv. Tanzânia submetido a intensidades e freqüências de corte. Em: Congresso de Forragicultura e Pastagens, 2. 2007. Lavras. Anais. UFLA. Lavras.

Pena, K.S., Zanine, A.M., Silva, W.L., Sousa, B.M.L., Nascimento Junior, D. e Silva, S.C. 2007 b. Acúmulo de forragem de Panicum maximum cv. Tanzânia submetido a intensidades e freqüências de corte. Em: Reunião Anual da Sociedade Brasileira de Zootecnia, 44. 2007. Jaboticabal. Anais... SBZ. Jaboticabal.

Rêgo, F.C.A., Damasceno, J.C., Cecator, U., Santos, G.T., Fukumoto, N. e Cortes, C. 2004. Disponibilidade dos componentes morfológicos da Brachiaria brizantha, dio capim Tanzânia e do Arachis pintoi, manejados em diferentes alturas. Em: Reunião Anual da Sociedade Brasileira de Zootecnia, 41. 2004. Campo Grande. Anais. SBZ. Campo Grande.

Reis, G.H.C., Oliveira, A.B., Pires, A.J.V., Mattos Neto, U., Santos, L.C. e Farias, M.A. 2006. Influência de diferentes adubações e alturas de corte nas características morfogênicas do Panicum maximum cv. Tanzânia. Em: Reunião Anual da Sociedade Brasileira de Zootecnia, 43. 2006. João Pessoa. Anais. SBZ. João Pessoa.

Richards, J.H. 1993. Physiology of plant recovery from defoliation. In: Baker, M.J. (Ed.). Grassland for our world. SIR Publishing. Wellington. pp. 4654.

Santos, M.S., Oliveira, M.E., Alves, A.A., Berchielli, T.T., Nascimento, C.B. e Veloso Filho, E.S. 2006. Capins Tanzânia e Marandu aos 22 e 36 dias de crescimento: produção e componentes morfológicos. Em: Reunião Anual da Sociedade Brasileira de Zootecnia, 43. 2006. João Pessoa.
Anais. SBZ. João Pessoa.

Schmidt, L.T., Dias, P.F., Souto, S.M., Rossiello, R.O.P. e Zanine, A.M. 2003. Absorção e acúmulo de nutrientes no capim cv. Tanzânia (Panicum maximum) em resposta à aplicação de nitrogênio como chorume bovino. Pasturas Tropicales, 25: 10-16.

Simon, L. 1999. Behaviour of Gliricidia sepium compared to Albizia procera in two silvopastoral systems. Pastos y Forrajes, 22: 365-369.

Soares, T.V., França, A.F.S., Oliveira, E.R., Magalhães, M.R.F., Matos, T.R.A., Sousa, V.R., Ribeiro, D.S. e Deus, F.E.G. 2004. Composição química do capim Tanzânia avaliado com doses crescentes de nitrogênio em duas alturas de corte. Em: Reunião Anual da Sociedade Brasileira de Zootecnia, 41. 2004. Campo Grande. Anais. SBZ. Campo Grande.

Souza, M.R.F., Pinto, J.C., Oliveira, I.P., Muniz, J.A., Costa, K.A.P., Rodrigues, R.B. e Nascimento, P.P. 2004a. Teores dos macronutrientes P, K, Ca e Mg na forragem do capim Tanzânia sob diferentes intervalos de corte. Em: Reunião Anual da Sociedade Brasileira de Zootecnia, 41. Anais. SBZ. Campo Grande.

Souza, M.R.F., Pinto, J.C., Oliveira, I.P., Muniz, J.A., Costa, K.A.P., Gomes, K.W. e Lima Filho, A.K. 2004b. IAF e relação folha/caule da forragem do capim Tanzânia sob diferentes intervalos de corte e doses de potássio. Em: Reunião Anual da Sociedade Brasileira de Zootecnia, 41. 2004. Campo Grande. Anais. SBZ. Campo Grande.

Souza, M.R.F., Pinto, J.C., Oliveira, I.P., Muniz, J.A., Rocha, G.P., Evangelista, A.R. e Costa, K.A.P. 2004c. Produção de forragem do capimTanzânia sob diferentes intervalos de corte e doses de potássio. Em: Reunião Anual da Sociedade Brasileira de Zootecnia, 41. 2004 Campo Grande. Anais. SBZ. Campo Grande.

Tonato, F., Pedreira, C.G.S., Moreno, L.S.B. e Pedreira, B.C. 2007. Produtividade e distribuição estacional da produção de cinco gramíneas do gênero Cynodon sob manejo intensivo. Em: Reunião Anual da Sociedade Brasileira de Zootecnia, 44. Jaboticabal. Anais. SBZ. Jaboticabal.

Zanine, A.M., Schimidt, L.T., Dias, P.F. e Souto, S.M. 2003. Produção e qualidade do capim Tanzânia (Panicum maximum) em diferentes idades e adubado com doses de $\mathrm{N}$ de chorume bovino. Pasturas Tropicales, 25: 30-36.

Archivos de zootecnia vol. 59, núm. 225, p. 91. 